\title{
A Critique of Amory Lovins' Soft Energy Path
}

\section{Ronald L. Simard

$$
\begin{aligned}
& \text { Vol. 4, No. } \\
& \text { EAPA } \\
& \text { 4:261 }
\end{aligned}
$$




\section{DISCLAIMER}

This report was prepared as an account of work sponsored by an agency of the United States Government. Neither the United States Government nor any agency Thereof, nor any of their employees, makes any warranty, express or implied, or assumes any legal liability or responsibility for the accuracy, completeness, or usefulness of any information, apparatus, product, or process disclosed, or represents that its use would not infringe privately owned rights. Reference herein to any specific commercial product, process, or service by trade name, trademark, manufacturer, or otherwise does not necessarily constitute or imply its endorsement, recommendation, or favoring by the United States Government or any agency thereof. The views and opinions of authors expressed herein do not necessarily state or reflect those of the United States Government or any agency thereof. 


\section{DISCLAIMER}

Portions of this document may be illegible in electronic image products. Images are produced from the best available original document. 


\section{Printed in the United States of America. Available from National Technical Information Service}

U.S. Department of Commerce

5285 Port Royal Road, Springfield, Virginia 22161

Price: Printed Copy $\$ 4.50$; Microfiche $\$ 3.00$

This report was prepared as an account of work sponsored by an agency of the United States Government. Neither the United States Government nor any agency thereof, nor any of their employees, contractors, subcontractors, or their employees, makes any warranty, express or implied, nor assumes any legal liability or responsibility for any third party's use or the results of such use of any information, apparatus, product or process disclosed in this report, nor represents that its use by such third party would not infringe privately owned rights. 
ORNL/TM-6233

Dist. Category UC- 80

Contract No. W-7405-eng-26

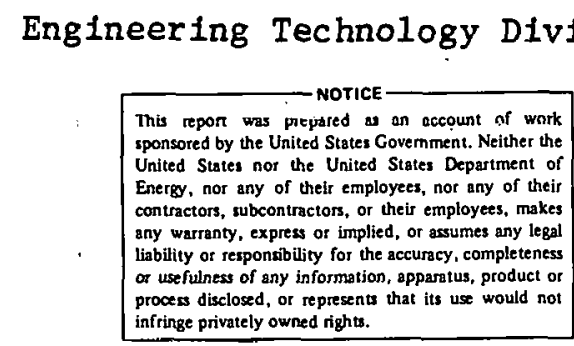

A CRITIQUE OF AMORY LOVINS' SOFT ENERGY PATH"

Ronald L. Simard

Manuscript Completed - March 27, 1978

Date Published - May, 1978

NOTICE: This document contains information of a preliminary nature. It is subject to revision or correction and therefore does not represent a final report.

Prepared by the

OAK RIDGE NATIONAL LABORATORY

Oak Ridge, Tennessee 37830

Operated by

UNION CARBIDE CORPORATION

for the

DEPARTMENT OF ENERGY 


\section{THIS PAGE}

\section{WAS INTENTIONALLY LEFT BLANK}


CONTENTS

$\underline{\text { Page }}$

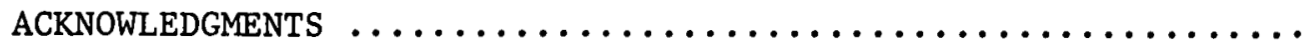

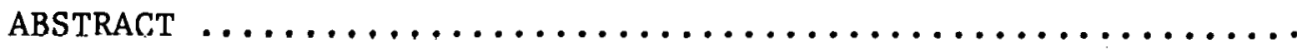

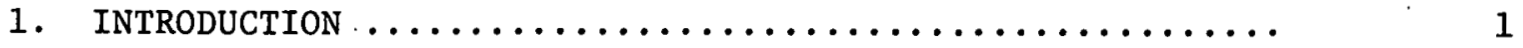

2. DEFINITION OF ENERGY PATHS, HARD AND SOFT ............

3. UNDESIRABLE CONSEQUENCES OF FOLLOWING THE HARD PATH .....

4. WAYS OF AMELIORATING THESE CONSEQUENCES $\ldots \ldots \ldots \ldots \ldots \ldots . \ldots$

5. DESIRABLE CONSEQUENCES OF FOLLOWING THE SOFT PATH ....... 12

6. WAYS OF SWITCHING OVER FROM HARD TO SOFT PATHS ......... 18

7. COMPARISON OF THE COSTS AND RISKS ASSOCIATED WITH EACH

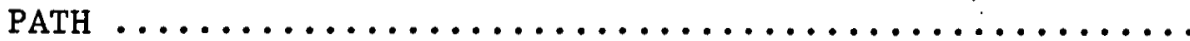

8. INTERNATIONAL IMPLICATIONS OF A DOMESTIC SWITCH FROM

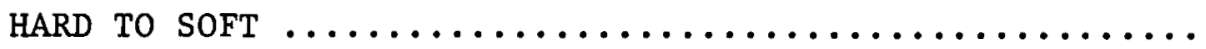

9. SOCIO-POLITICAL IMPACT OF SUCH A SWITCH ............... 29

10. ENERGY POLICY AS A CATALYST FOR SOCIAL CHANGE .......... 33

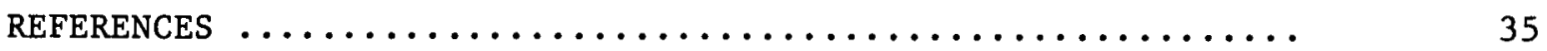

Appendix A. THE COST OF NUCLEAR-GENERATED ELECTRICITY IN

THE MID-1980s, AS CALCULATED BY LOVINS ........ 
THIS PAGE

\section{WAS INTENTIONALLY \\ LEFT BLANK}


ACKNOWLEDGMENTS

This work was sponsored by the Office of Energy Technology-Nuclear, Department of Energy. 


\title{
A CRITIQUE OF AMORY LOVINS' \\ SOFT ENERGY PATH
}

Ronald L. Simard

\begin{abstract}
Our current energy policy is characterized by Amory Lovins as relying upon the rapid expansion of centralized "hard" technologies to increase supplies of energy, especially in the form of electricity: it is criticized for diverting large amounts of capital from other sectors of the economy, imposing undesirable life styles upon energy users, and enhancing the proliferation of nuclear weapons.

An alternative policy is offered by Lovins which relies upon diverse, renewable energy sources. These "soft" technologies are characterized as more flexible and less complicated than the hard technologies and are better matched in scale and energy quality to end-use needs. Combined with conservation and technical fixes to improve efficiency and reduce overall demand from current projections, these systems are to supply all domestic energy needs by the year 2025 .

Lovins' scenario has been reviewed by three consulting groups under subcontract to Oak Ridge National Laboratory (ORNL). Their opinions are summarized herein.
\end{abstract}

\section{INTRODUCTION}

Amory Lovins is a consultant-physicist, the British representative of Friends of the Earth. His criticisms of current energy strategies and his version of a desirable domestic strategy for the future have been set forth in a recent book, ${ }^{1}$ symposium proceedings, ${ }^{2}$ and a journal article. ${ }^{3}$ The impact that his views are having may be gauged from a report that the journal, Foreign Affairs, has received more requests for reprints of his article than for any other article in its history.

To assist staff in the U.S. Energy Research and Development Administration Division of Nuclcar Research and Appllcations in evaluating Lovins' energy strategy, three consulting groups were asked to review and comment upon his work. ${ }^{4-6}$ The groups are:

1. Energy Research Group (ERG)

2. Donovan, Hamester, and Rattien (DHR)

3. University of California, Davis, Council on Energy and Resources (UCD). 
Their findings are summarized herein in the form of responses, on a point-by-point basis, to the main points raised by Lovins in his Foreign Affairs article. The article covers the following areas:

Definition of energy paths, hard and soft Undesirable consequences of following the hard path Ways of ameliorating these consequences Desirable consequences of following the soft path Ways of making the transition from hard to soft paths Comparison of the costs and risks associated with each path International Implications of a domestis shift from hard to ooft

Socio-political impact of such a switch

Energy policy as a catalyst for social change

and reviewer comments in each of these areas have been culled from their reports. 


\section{DEFINITION OF ENERGY PATHS, HARD AND SOFT}

\subsection{Lovins}

The hard path "resembles present federal policy and is essentially an extrapolation of the recent past. It relies on rapid expansion of centralized high technologies to increase supplies of energy, especially in the form of electricity. The second (soft) path combines a prompt and serious commitment to efficient use of energy, rapid development of renewable energy sources matched in scale and in energy quality to enduse needs, and special transitional fossil-fuel technologies."

The two paths are described as mutually exclusive. Lovins argues that a commitment to the soft path is preferable and must be made soon before the consequences of following the hard path prevent making the switch.

\subsection{Energy Research Group}

Hard and soft technologies need not be mutually exclusive. There is evidence that they "can and must co-exist, as well as the clear demonstration of the compatibility of conservation and hard technology. There is no reason why a belief in the necessity of maintaining current hard technologies and the desirability of developing new ones should be incompatible with a belief in the necessity of conservation and the desirability of implementing appropriate soft technologies."

\subsection{Donovan, Hamester and Rattien}

DHR also criticizes the claim of mutual exclusivity and points out that even if a complete commitment to the soft path were made, the changeover would take quite a while. More realistically, the mix of energy options in the future will combine the best features of both paths. "To suppose otherwise assumes a social consensus never matched before." 


\subsection{University of California, Davis}

The UCD report takes the approach that classifying the two paths as mutually exclusive is regrettable because "it dismisses a priori the promise of what could be a new and interesting combination of hard and soft technologies - a combination which may be extremely effective in allowing a soft technology path to function effectively on a national scale." Furthermore, "however correct the arguments Lovins and others have put forth against large scale, high technology energy development, they constitute only the basis of a rationale for exploring other paths, not a case for adopting any particular pach." 


\section{UNDESIRABLE CONSEQUENCES OF FOLLOWING THE HARD PATH}

\subsection{Lovins}

Lovins' projects hard path requirements of 450 to 800 nuclear reactors in the year 2000 "including perhaps 80 fast breeders, each loaded with 2.5 metric tons of plutonium, 500 to 800 huge coal-fired power stations, 1000 to 1600 new coal mines and some 15 million electric automobiles." The corresponding energy requirements for this mix of hard technologies is estimated to be 160 quads $\left(10^{15} \mathrm{Btu}\right)$ per year by the year 2000 .

This scenario is criticized because of its adverse environmental impact, inefficient use of resources, and enormous capital intensity.

The environmental impacts include "the release of waste heat sufficient to warm the entire freshwater runoff of the contiguous 48 states by $34-49^{\circ} \mathrm{F}$. Mining coal and uranium, increasingly in the arid West, entails inverting thousands of communities and millions of acres, often with little hope of effective restoration. The commitments to a longterm coal economy many times the scale of today's makes the doubling of atmospheric carbon dioxide concentration early in the next century virtually unavoidable, with the prospect then or soon thereafter of substantial and perhapo irreversible changes in global climate."

Shortages in oil and natural gas are predicted. "Worse, at least half of the energy growth never reaches the consumer because it is lost earlier in elaborate conversions in an increasingly inefficient fuel chain dominated by electricity generation (which wastes about two-thirds of the fuel) and coal conversion (which wastes about one-third). Thus in Britain since 1900, primary energy - the input to the fuel chain - has doubled while energy at the point of end use - the car, furnace or machine whose function it fuels - has increased by only a half, or by a third per capita; the other half of the growth went to fuel the fuel industries, which are among the largest energy consumers."

In addition to adverse environmental impacts and shortages, one of the biggest barriers to implementing the projected hard path requirements is their capital costs. For example, Lovins estimates that ex-President Ford's 1976-1985 energy program would have cost "over \$1 trillion (in 
1976 dollars) in initial Investment, of which 70 to $80 \%$ would be for new rather than replacement plants." These long-lead-time, long-payback-time investments are characterized as highly inflationary and a tremendous strain on the investment structure. Three-fourths of the \$1 trillion figure cited would go into electrification and the "combination of disproportionate and rapidly increasing capital intensity, long lead times, and economic responses is already proving awkward to the electric utility industry. . . ." The industry finds inself, in Lovins' view, in a "spiral of impossibility" as "large capital programs $\longrightarrow$ poor cash flow $\longrightarrow$ higher electririty prices $\longrightarrow$ reduced demand growth $\longrightarrow$ worse cash flow, . ." cte.

\subsection{Energy Research Group}

The ERG report does not address Lovins' estimates of environmental impact or projections of 450 to 800 nuclear reactors, etc., but it does present a comparison of estimates of U.S. energy demand in the year 2000 taken from a variety of sources. None of the estimates is as high as Lovins' figure of 160 quads and the average overall estimates is only 118.8 quads.

The report contains a good discussion of patterns of energy use and energy/output ratios. While recognizlng the need for improvement in efficiency of resource utilization, the ERG report presents a different picture of historical trends, e.g., a figure shows U.S. per capita output energy increasing fivefold since 1920 (compare with Lovins' claim that British end-use energy per capita has 1ncreased by only one-third sinos 1900).

While pointing out that lovins overestimates hard path costs (particularly for nuclear power), the report agrees with Lovins that "very high" year 2000 supply scenarios of over 150 quads are "intractable" because of the large amount of capital investment required [in excess of $3 \%$ of cumulative gross national product (GNP)]. 


\subsection{Donovan, Hamester and Rattien}

The DHR report points out that an energy demand of 160 quads by the year 2000 "is on the high side of the range of current accepted estimates." However, even the use of a more realistic growth rate would imply "a huge capital outlay, and Lovins' points concerning the unhealthy economic effects of such large, long-payback investments in one sector of the economy are well taken."

\subsection{University of California, Davis}

The UCD report contains no quantitative appraisal of these points and makes the claim that ". . . we do not believe that specific numbers are the key to understanding the issues raised by Lovins. Indeed, too much emphasis at this point upon them can readily distract attention from the fundamental issues raised." However, some of Lovins' energy growth and decay rates are compared with other estimates, primarily those of ERDA-48 (1975), and found to be reasonable. 


\section{WAYS OF AMELIORATING THESE CONSEQUENCES}

\subsection{Lovins}

According to Lovins; there are basically two ways to do more with less energy. Technical fixes "use today's technologies, are advantageous today by conventional economic criterla, and have no significant effect on 1ife styles... ." Examples include cogeneration, thermal insulation, heat pumps, more efficient furnaces and automobile engines, etc. Or, "we can make and use a smaller quantity or a different mix of the outputs themselves, thus to some degree changing . . our life styles." Examples include car-pooling, smaller cars, use of mass transit systems, etc.

Lovins feels that with technical fixes alone, we could improve energy efficiency, "in the long term," by: a factor of three or four, and he cites a source which claims that, using those technical fixes which could be implemented by the turn of the century, we could nearly double the efficiency with which we use energy.

As an example of the possible impact of technical fixes, he points to Sweden and West Germany. "Americans would still use about a third less energy than they do now if they were as efficient as the Swedes.... U.S. per capita energy intensity, too, is about twice that of west Germany in space heating, four times in transport." As further examples, he offers conservation and cogeneration.

The capital savings possible with conservation are said to be impressive. ". . . the investments needed to save the equivalent of an extra barrel of oil per day are often.. . far less than the amounts needed to increase most kinds of energy supply."

As for cogeneration (the generation of electricity as a by-product of industrial process steam), Lovins quotes an estimate that "by 1985 U.S. industry could meet approximately half its own electricity needs (compared to about a seventh today) by this means." Again using West Germany as an example, he claims that "cogeneration provides about $4 \%$ of electricity today in the United States but about $29 \%$ in West Germany. Cogeneration and more efficient use of electricity could together reduce 
our use of electricity by a third and our central-station generation by $60 \%$ "

Lovins feels that the scope for technical fixes is so great that "we could spend several hundred billion dollars on them initially plus several hundred million dollars per day - and still save money compared with increasing the supply."

The reason we are not embarked fully on such a program now is not technical or economic: it is due to the existence of a "wide array of institutional barriers, including more than 3000 conflicting and of ten obsolete building codes, an innovation-resistant building industry, lack of mechanisms to ease the transition from kinds of work that we no longer need to kinds we do need, opposition by strong unions to schemes that would transfer jobs from their members to larger numbers of less 'skilled' workers, promotional utility rate structures, . . " etc.

By addressing these institutional problems and by introducing "sound" economic principles such as inverted utility rate structures, life-cycle costing and properly assessing environmental costs, we should be able to improve our energy efficiency significantly and not have to introduce social changes, or changes in life style. In fact Lovins feels that "we should be able to double end-use efficiency by the turn of the century or shortly thereafter, with minor or no changes in lifestyles or values."

As a "basis for a coherent alternative" to the usual hard path forecasts, Lovins assumes a primary energy demand of 95 quads as being possible for the year 2000 with total energy demand gradually declining thereafter "as inefficient buildings, machines, cars and energy systems are slowly modified or replaced."

\subsection{Energy Research Group}

The ERG report says that comparisons of per capita energy consumption or energy/gross domestic product (GDP) among different countries can be misleading because mixes of goods and services may be different with different proportions of energy-intensive products. Even when the mixes are roughly similar, the energy needed to produce, transport, and distribute 
given products may vary. They quote a study of five industrial countries where "about one-half of the difference between the energy/GDP ratios of those countries and that of the United States is attributable to differences in the composition of goods and services relative to the U.S. The other half (roughly) is a product of two factors - the energy intensity per task in each country and an 'interaction' effect attributable to both the kinds of tasks and the energy intensity of each task."

The ERG report also recognizes the benefits of cogeneration but points out the following institutional barriers to its widespread use:

1. geographic mismatches of primary production and "byproduct" demand (thus Lovins' suggestion that the U.S. could satisfy its electrical needs in the late $1980^{\prime}$ 's with a combination of technical fixes, presents hydroelectric capacity, and cogeneration capacity involves severe geographical mismatches).

2. the need to site generating capacity away from large population centers and community resistance to its location near the community,

3. regulatory problems (environmental, financial, etc.), and

4. Inadequate incentives for an industry to cogenerate more than its own needs.

Regarding the lack of incentives for industry to adopt cogeneration, the report uses as an example one particular cogeneration system which would replace the equivalent, separate, boilers and power plant, and notes "an $80 \%$ increase in fuel procurement and a $120 \%$ increase in emissions as well as the increased capital cost. It is difficult to convince an industrial concern to accept this burden unless it plans to use a significant fraction of the power, or is given sufficient financial inducement (such as a high tax credit or high rate of return), or has the utility cover part of the construction costs. In fact, given current institutional problems of coal use, it may be difficult enough to get the industrial producer to switch from fluids to coal, let alone to install cogeneration."

However, the report acknowledges the increased efficiency, capital savings, and benefits that would accrue to society as a whole from 
increased cogeneration capacity and recognizes the need to remove these institutional barriers.

\subsection{Donovan, Hamester and Rattien}

Additional institutional and implementation barriers to cogeneration identified in the DHR report include

1. Interfacing between the industry and the local utility. How should the electricity sold to the utility be treated - as fuel savings, capital savings, or both? How would the timing of the availability of the electricity affect the exchange rates?

2. Regulatory problems for the industry. If the industry owns the cogeneration system, it would be subject to Public Utility Commission regulation of rates and financial practices; as well as federal and state regulation of environmental impact.

3. Problems for the utility. If the utility controls the cogeneration system, how would it "deal with strikes by the industry's labor organizations?" How would it deal with "reduced demand for the industry's product?" How would it "coordinate power production with industry schedules to maintain overall system reliability, synchronization, and voltage standards?" How would it "manage investment in new power capacity in conjunction with industry plants?"

Some environmental and social impacts of cogeneration and district heating are alsn addressed and are described in sect. 7.

\subsection{Universtty of California, Davis}

The UCD report points out that efficiency has often been sacrificed for flexibility. A characteristic of systems with high thermodynamic efficiency, such as likely cogeneration systems, is their careful design with "tightly interconnected" elements. It becomes "exceedingly difficult to redesign or change in any major way any individual portion of a plant." 
5. DESIRABLE CONSEQUENCES OF FOLLOWING THE SOFT PATH

\subsection{Lovins}

The "soft" path is defined by the rapid deployment of "soft" technologies. There are five characteristics of soft technologies: They are:

1. renewable,

2. diverse,

3. flexible,

4. matched in scale, and

5. matched in quality to end-use needs.

That is,

1. They rely on renewable energy sources.

2. They rely on diverse energy sources "so that energy supply is an aggregate of very many individua11y modest contributions, each designed for maximum effectiveness in particular circumstances."

3. They are flexible and less complicated than hard technologies ("accessible rather than arcane").

4. They are matched in scale and geographical distrihution tn end=use needs.

5. They are matched in energy quality to end-use needs.

The major candidates which meet these criteria are solar heating and cooling, biomass conversion, and wind-hydraulic systems. Solar heating and cooling is clalmed to be cheaper than present electric heating virtually anywhere in the U.S., cheaper than oil heat in many parts of the U.S., and cheaper than heating with gas and coal in some parts. Biomass conversion, on a "reasonable" scale (roughly 1,0 to 14 times the fluid output of our domestic wine and beer industries), could meet all our transportation needs early in the next century (assuming a "reasonable" threefold increase in overall efficiency). Wind-hydraulic systems "already seem likely in many design studies to compete with nuclear power in much of North America and Western Europe." 
Energy storage is not a major problem when these technologies are employed at the appropriate scale. "Daily, even seasonal, storage of lowand medium-temperature heat at the point of use is straightforward with water tanks, rock beds, or perhaps fusible salts. Neighborhood heat storage is even cheaper. . . On the whole, therefore, energy storage is much less of a problem in a soft energy economy than in a hard one." The appropriate scale at which technologies are to be employed also allows at least five types of economies not available to larger, more centralized systems. First, overhead costs are reduced, e.g. "For electrical and some fossil-fuel systems, distribution accounts for more than half of total capital cost, and administration for a significant fraction of total operating cost."

Second, distribution losses are eliminated.

Third, "Small systems also avoid direct diseconomies of scale, such as the frequent unreliability of large units and the related need to provide instant 'spinning reserve' capacity on electrical grids to replace large stations that suddenly fail."

Fourth, "Small systems with short lead times greatly reduce exposure to interest, escalation, and mistimed demand forecasts - major direct diseronomies of large scale."

The fifth kind of economy is that possible with mass production.

There are medium scale as well as small scale applications possible. For instance, urban neighborhoods or rural villages can employ solar collectors and communal heat storage systems, thereby reducing the need for extensive retrofitting of individual buildings.

Equally important is the matching of energy quality and end-use needs. According to Lovins' classification of end-use needs, about $58 \%$ of all energy at the point of end use is required as heat in the U.S.: $38 \%$ goes into mechanical motion; only " $8 \%$ of our energy end use, then, requires electricity for purposes other than low-temperature heating and cooling. Yet, since we actually use electricity for many such low-grade purposes, it now meets 13 percent of our end-use needs - and its generation consumes 29 percent of our fossil fuels. . . Plalnly we are using premium fuels and electricity for many tasks for which their high energy 
quality is superfluous, wasteful and expensive, and a hard path would make this inelegant practice even more common."

The $8 \%$ total of end uses which require electricity could be reduced to about $5 \%$ via certain technical fixes. Lovins claims that at this level "we could probably cover all those needs with present U.S. hydroelectric capacity plus the cogeneration capacity available in the mid-to late 1980s. Thus an affluent industrial economy could operate with no central power stations at all!"

Lovins presents a "plausible and realistic" growth pattern for soft technologies which could replace even optimistic projections of nuclear output in the 1990 s and meet virtua11y all our energy needs by 2025 . He contrasts this with hard path projections hy pointing nut that "roughly half" plus "a further appreciable fraction" of the gross primary energy produced in the hard path is lost in conversions to end use and in distribution. Thus at the point of end use, the amount of energy available "is thus not vastly greater than in the soft path, where conversion and distribution losses have been all but eliminated. But the soft path makes each unit of end-use energy perform several times as much social function as it would have done in the hard path; so in a rnnventinnal sense, social welfare in the soft path in 2025 is substantially greater than in the hard path at the same date."

\subsection{Energy Research Group}

The ERG report attributes the "disproportionately" large rontrihutinn uf electrlcity to end-use energy production to its convenience and predicts future growth for the following reasons

1. increased demand of electrical end uses

2. convenience, particularly in inter-fuel switching

3. institutional problems for direct coal use

4. limits to nonelectrical energy source production

Because of natural gas shortages and the precariousness of oil supply since the embargo, many industries "may prefer to switch to electricity and pay the price premium rather than become embroiled in fuel procurement problems or in Federal, State and local regulations over coal use - leaving 
utilities to act as their surrogate in procurement and regulatory matters."

There may be mismatching between energy quality and end-use needs but "where a mismatched energy source is economically competitive, some other resource, such as labor or capital, is being conserved more efficiently. Thermodynamics is not the final criterion."

The capital requirements associated with the suggested soft path are described in Sect. 7. Although Lovins suggests only "reasonable" goals for the year 2000 on (e.g., a year 2000 demand of 95 quads - 25 from coal, 35 from oil and natural gas, and 35 from soft technologies) and does not break down these goals according to end-use, such an attempt is made in the ERG report "following Lovins' suggestions as closely as possible." It can be seen that "monumental changes are required even by 2000 (with just $37 \%$ 'soft' energy as compared to $1.00 \%$ by 2025):

1. $60 \%$ of all industrial process steam boilers are converted to coal-fired, fluidized-bed, gas turbine cogeneration systems;

2. $121 / 2 \%$ of industrial steam boilers are coal-fired and $271 / 2 \%$ are solar-powered;

3. all industrial heating is converted to gas;

4. all cooking and drying is converted to gas;

5. virtually all residential and commercial space is equipped with high-efficiency solar heating ( $70 \%$ of space heat, $83 \%$ of water heat) with natural gas backup;

6. $55 \%$ of cooling is solar with electric backup;

7. electricity demand is $23 \%$ higher than 1975 ( $57 \%$ cogenerated $151 / 2 \%$ wind, $151 / 2 \%$ hydro, $12 \%$ coal);

8. $40 \%$ of transportation demand is provided by biomass alcohol. - . the changes required seem hardly less staggering than for Lovins' hard path, particularly if the associated support facilities and infrastructure changes are included."

\subsection{Donovan, Hamester and Rattien}

The DHR report calls Lovins' projections of 5 quads in 1985 and 35 quads ( $37 \%$ of total needs) in 2000 from soft technologies "highly 
improbable." Other "more realistic" projections are cited which put "renewable energy source contributions at $4 \%$ to $6 \%$ by 2000 under favorable conditions (these are percentages of presumably larger totals, however."

The contribution projected for biomass conversion might be accurate but Lovins' calculations are "misleading in terms of the scale-up implied to produce one-third of our current gasoline consumption. A cursory reading leaves the impression that a scale-up of 10-14 times would satisfy this demand; the actual ratio implicit in Lovins calculations is about 150 times."

In defense of Lovins, the DHR report notes that

"Some have argued that if Lovins' soft path were, in fact, technologically feasible, publicly acceptable, environmentally sound and cost effective, our energy policy would have naturally developed along the lines he has proposed - the fact that it has not is testimonial to the inherent inadequacy of his energy strategy. This criticism seems unfair at this stage for a number of reasons:

1. Energy has been relatively inexpensive (indeed declining in real cost) because of an apparent abundance of energy resources, improved economies of scale and government subsidies to certain sectors of the industry. There seemed little reason to change the system as long as it maintained growth rates.

2. Powerful pro-growth vested interests would be expected to resist changes in the system which signify low growth (i.e., small investments).

3. The actual physical energy infrastructure is itself so extensive as to discourage deviations from it [e.g., although district heating is quite economic as a total system, the cost and problems associated with now installing a steam-heat distribution system in urban areas are substantial in comparison to the use of less efficient but existing capital stock (electricity and gàs distribution systems)].

4. The validity of life-cycle costing, environmental economics and renewable resources are just becoming recognized, while at the 
same time, the long-assumed correlation between social well-being and energy growth is beginning to be seriously questioned."

\subsection{University of California, Davis}

In addition to the possible trade-offs between energy efficiency and other resources like labor or capital, another consideration is the interaction of efficiency and flexibility. "A characteristic of systems with high thermodynamic efficiency is that they are carefully designed, and the elements are tightly interconnected. Under these circumstances it becomes exceedingly difficult to redesign or change in any major way any individual portion of a plant. . . An advantage of inefficiency is that it provided flexibility - both of process design and of process and plant location. . . It is presently unknown to what degree thermodynamic matching of energy sources to loads might impede industrial output growth."

The UCD report finds Lovins' demand projections to be reasonable, on the whole, with two exceptions. First, his total energy input in 2025 of 63 quads is considered "exceptionally low by any standards." Second, his projection of coal uses in 2000 would mean "an increase in coal use from a present 15 quads (about 650 million tons per year) to 29 quads (about 1.3 billion tons per year)." Production of this much coal "would require extensive increases in coal mining, with the attendant environmental problems from mining, combusion, etc. It is by no means clear that such expansion is consistent with the philosophy of a 'soft technology' future. Technologies for coal production at this level are known which would be massive in size, centralized in management, expensive, and requiring extensive new transportation networks." 


\section{WAYS OF SWITCHING OVER FROM HARD TO SOFT PATHS}

\subsection{Lovins}

The recommended way to switch from one path to the other, "to build a bridge to the energy-income economy of 2025," is through the development of transitional technologies which exploit "briefly and sparingly" our coal resources.

Examples of suitable transitional technologies include the cogeneration of electricity from existing industrinl steam processes and thc use of waste heat for district heating, as woll ao ocvcral "sophisticaled" uses of coal - supercritical coal gasification, flash hydrogenation, flash pyrolysis, panel-bed filters and "similar ways to use coal cleanly at essentially any scale and to cream off valuable liquids and gases as premium fuels before burning the rest." Lovins is particularly optimistic about the use of fluidized-bed burners, claiming that they are "simple, versatile," "ready to be commercially applied to raising steam and operating turbines," and flexible in scale. "Fluidized bed boilers and turbines can power giant industrial complexes, especially for cogeneration, and are relatively easy to back fit into old municipal power stations. Scaled down, a fluidized bed can be a tiny household device - clean, strlkingly simple and flexible - that can replace an ordinary furnace or grate and can recover combusion heat with an efficiency over $80 \%$. At medium scale, such technologies offer versatile boiler backfits and improve heat recovery in flues."

The scale employed can also be adjusted to allow the plugging in of soft technologies later. For example, neighborhood-sized hot water tanks in a transitional district heating scheme "can in the long run be heated by neighborhood solar collectnrs, wind-driven heat pumps, a factury, a pyrolyzer, a geothermal well, or whatever else becomes locally available. . . "

The idea is to use coal, conservation, and soft technologies together such that "most of the frontier extraction and medium-term imports of oil and gas become unnecessary and our conventional resources are greatly stretched. Coal can fill the real gaps in our fuel economy with only a 
temporary and modest (less than twofold at peak) expansion of mining, not requiring the enormous infrastructure and social impacts implied by . . ." Lovins' projections of the hard path future.

\subsection{Energy Research Group}

The ERG report makes no specific comments on Lovins' suggested transitional technologies but notes the environmental problems to be expected with the widespread use of fossil fuels, i.e., "With dispersal, pollution control is more difficult, less amenable to regulation, and hardly more environmentally sound than the 'hard' path."

\subsection{Donovan, Hamester and Rattien}

Lovins' view of the state of the art of fluidized bed technology is challenged by the DHR report, e.g., "Small scale fluidized bed technology that may be useful for a single dwelling unit is still far in the future for the U.S. The cost and environmental consequences of such a system are, therefore, quite unknown. A significant need exists to redevelop an infrastructure to transport, deliver and store coal and to remove the wastes. We are once again faced with the problem of control and the simple danger of many energy conversion systems running without adequately trained operators supervising their functioning to help assure adequate safety and environmental control." Also," . . there are emissions uncertainties which must be rectified hefore these burners are applicable on a wide scale. This would also require a complex institutional monitoring and evaluation structure to deal with countless small point sources of emissions."

In addition, the report cites the Council for Energy Independence 7 rough calculations of the cost of "home fluidized-bed coal burners for the U.S. housing stock using basically favorable single system prices and investment terms." The widespread use of such burners is expected to cost "hundreds of billions of dollars."

Further, Lovins fails to account for the very real problems of "transition that would be encountered in moving from the existing hard 
technologies to their soft alternatives. The rate at which efficiency improvements and soft energy technology are introduced in our economy would at best be equal to (in lieu of policy actions) the rate of addition to, replacement of, or improvement in capital stock.

These rates of change in the current stock of automobiles, houses, and industrial installations would presumably reflect an analysis of their cost-effective utilization over time. Unless restrictive government mandates are used, however, it would appear likely that only a fraction of such additions, replacements or improvements over the next two or three decades will utilize the technologies associated with the soft path, for a variety of environmental, economic and institutional reasons. If a workable (acceptable economic impacts) policy strategy does not really exist to effect this transformation rapidly, then the energy demand levels projected by Lovins' Road-Not-Taken for the post 2000 period will be nothing more than hopeful speculation."

"The most likely adoption of the soft path would first be a mixed system of centralized production of electricity, oil and gas, supplemented by decentralized use of solar heating systems. Early applications of the soft technologies are most likely for dispersed, often isolated rural energy needs, while existing urban developments continue to rely on the developed energy infrastructure and centralized power sourcee. In govcrnmental pulicy as well, the most probable real world outcome is that neither road will be taken to the exclusion of the other."

\subsection{Iniverssity of Californiạ. Davia}

The UCD report does not directly address the problems of transition from the hard to the soft path but makes the comment that technologies ful cual production at the levels required "would be massive in size, centralized in management, expensive, and requiring extensive new transportation networks." 
7. COMPARISON OF THE COSTS AND RISKS ASSOCIATED WITH EACH PATH

\subsection{Lovins}

In general, the cost advantages of the soft path arise because the soft technologies have, first, much lower and stable operating costs than the hard technologies and, second, lower initial costs due to "technical simplicity, small unit size, very low overheads, scope for mass production, virtual elimination of distribution losses and of interfuel conversion losses, low exposure to escalation and interest, and prompt incremental construction (so that new capacity is built only when and where it is needed)."

The estimated capital costs are expressed in terms of equivalent barrels of oil (one bbl/day $=67.1 \mathrm{~kW}$ ). Lovins' estimates for hard, soft, and transitional technologies per day (in constant 1976 dollars) are shown in Table 1, taken from his testimony during a Congressional hearing on the costs of nuclear power. ${ }^{8}$

The total capital investment associated with the hard path (e.g., ex-President Ford's 1976-1985 energy program) is over \$1 trillion (threefourths for electrification). No corresponding estimate is presented for the soft path. The capital would be raised differently, e.g., " . . solar investments are borne by the householder, electric investments by a utility that can float low-interest bonds and amortize over 30 years. During the transitional era, we should therefore consider ways to broaden. householders' access to capital markets. For example, the utility could finance the solar investment (leaving its execution to the householder's discretion), then be repaid in installments corresponding to the householder's saving."

The risks associated with each path are classifed in terms of economic risks and environmental impacts. For example, the hard path

1. relies on a few technologies whose success is not certain,

2. relies on technologies vulnerable to error, accidents, and sabotage, 
Table 1. Approximate marginal capital investment (1976 \$) needed to build complete energy systems to deliver energy to U.S. consumers at a rate equivalent to one barrel of oil per day (about

67 kilowatts) on a heat-supplied basis (enthalpic, without regard to quality of energy supplied) assuming present technologies ${ }^{\alpha}$

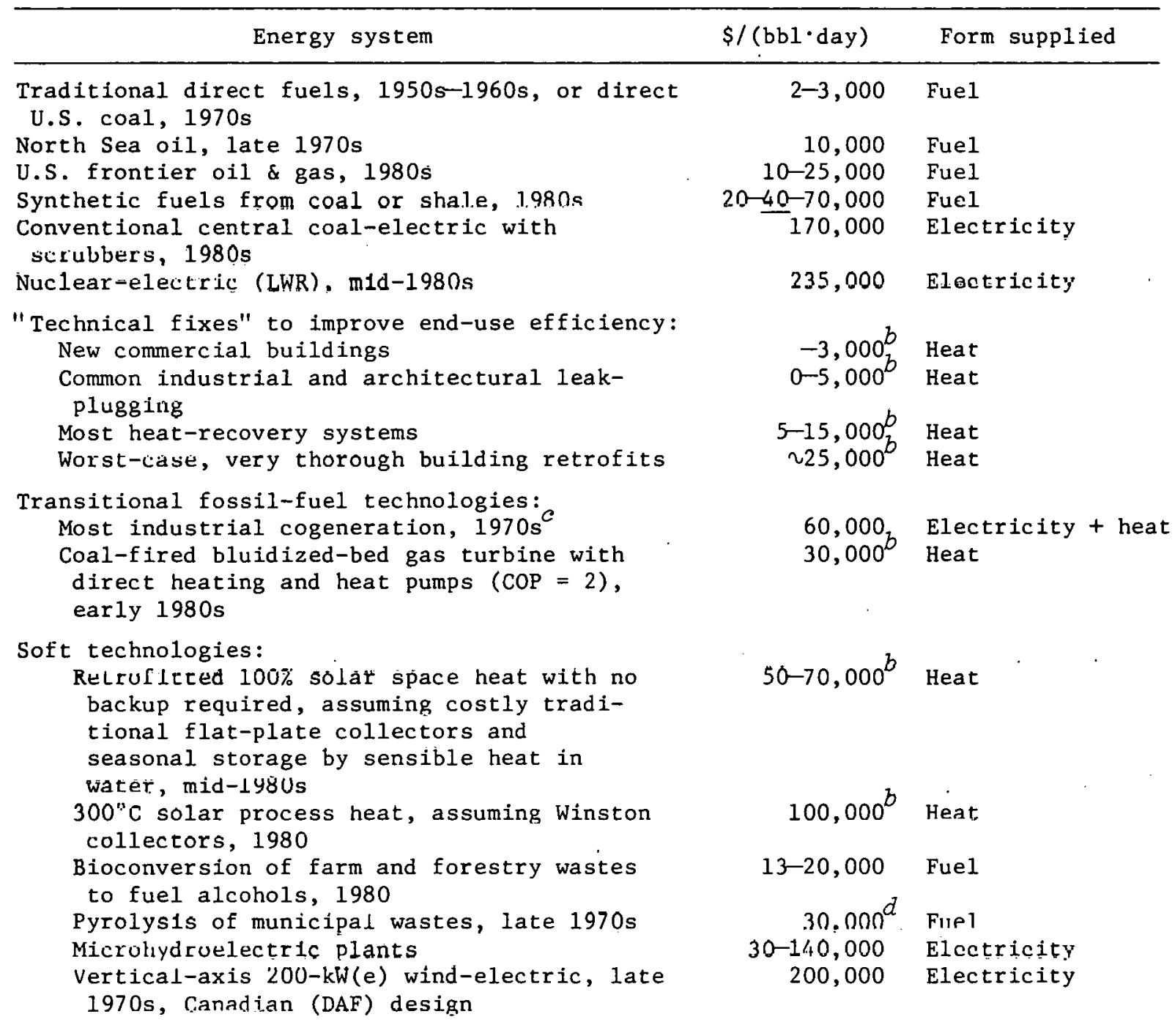

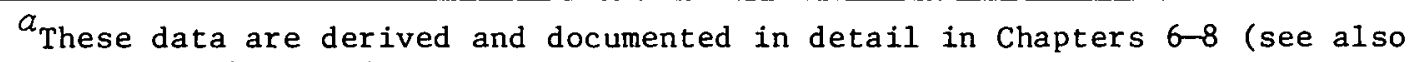
Chapters 1 and 3 ) in Ref. 1 .

$b$ expensive: an unpublished 1976 Shell analysis calculates typical capital requirements, in ul976 dollars per primary bbl/d used, of order $\$ 120-200,000$ for a European car, $\$ 35,000$ for a conventional house heating system, $\$ 5-10,000$ for industrial boilers, and $\$ 14,000$ for a blast furnace.

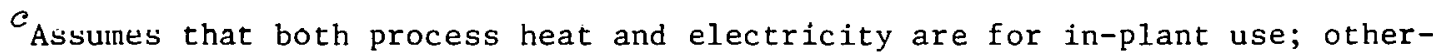
wise a modest sum should be added for marginal electric distribution facilities.

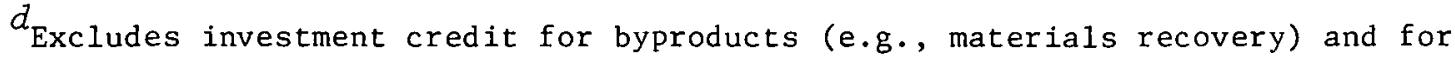
waste disposal services replaced. 
3. will fail "with widespread and serious disruption, if any of its exacting technical and social conditions is not satisfied continuously and indefinitely."

While the soft path

1. distributes the risks among several diverse, less complicated, technologies "most of which are already known to work we11,"

2. relies on diverse energy sources which are not as vulnerable to error, accidents, and sabotage,

3. is more flexible - and thus robust. Its technical diversity, adaptability, and geographic dispersion make it resilient and offer a good prospect of stability under a wide range of conditions, foreseen or not.

The environmental risks associated with the hard path are poorly understood and some "have probably not yet been though of." The possibility of near-term climatic constraints on coal combustion is brought up. The environmental effects of the soft path, however, "are relatively small, tractable and reversible."

\subsection{Energy Research Group}

The ERG report criticizes Lovins' use of dollars per equivalent barrel of oil per day in estimating capital costs for two reasons - it doesn't take into account capital replacement or differing efficiencies of end use. By putting oil and gas production on a life cycle equivalent to electric power production, the ERG calculates a marginal capital cost for oil. and gas production about one-half that for electricity (vs the approximate factor of 10 shown in Table 1 ).

Lovins' comparison of direct fuel costs and electricity costs is also criticized because Lovins "while meticulous about infrastructure costs and $T \& D$ losses for electricity generation, neglects refining, transportation and other costs and losses for 'direct' fuel use."

His calculation of nuclear electricity costs are said to be too high by a factor of 2 - a "reasonable" estimate of $\$ 140,000$ dollars (1976) per barrel per day for a nuclear unit in the mid-1980's is presented (vs the $\$ 235,000$ shown 1n Table 1$)$. Also see Appondix $\Lambda$. 
Not only are hard path costs overestimated, but soft path costs are considerably underestimated. Rough calculations are done for a variety of wind-electric systems and the results (In 1976 dollars) range from $\$ 275,000$ to $\$ 548,000$ per barrel per day (vs the $\$ 200,000$ shown in Table 1 ). Rough calculations are presented, too, for $100 \%$ solar space heating and again the ERG result is considerably higher than Lovins' - $\$ 470,000$ per barrel per day (vs the $\$ 50,000$ to $\$ 70,000$ shown in Table 1 ).

The total capital cost of the soft path to the year 2000 is also estimated. In 1976 dollars,

1. \$2.5 trillion $1 \mathrm{~s}$ allocated for the development of the 35 quads from sofl lechuvlogles which Lóvins calls tor,

2. $\$ 400$ billion is allocated for the 60 quads to he obtained from coal, oil and gas in the year 2000, and

3. $\$ 180$ billion is allocated for the early retirement of centralized electricity production and associated transmission structures. The considerable uncertainties associated with these numbers are acknowledged and estimated: the resultant cost (in 1976 dollars) of following the soft path to the year 2000 is put at $\$ 2.1$ to $\$ 4.1$ trillion. This corresponds to "about $51 / 2 \%$ of cumulative GNP for the period 1975-2000" and is $2-4$ times the $\$ 1$ trillion figure attached by Lovins to ex-President Ford's energy program. Thus, the same capital constraints (or worse) would apply to Lovins' soft path which he applies to the hard path.

The ERG report cautions, however, that this analysis does not argue against a "realistic" deployment of soft technologies. "Obviously, some soft technologies can provide less expensive energy than competing hard technology supply, even at higher capital cost. This applies, for example, to the use of solar hot water heating or to the substitution of solar space heating for electric resistance heating in many regions."

The ERG report admits that "the deployment of solar-based energy sources to the maximum extent feasible is obviously desirable in terms of their low environmental impact" but notes that the dispersed use of fossil fuels, particularly in the transitional stage, can make pollution control "more difficult, less amenable to regulation, and hardly more environmentally sound than the 'hard' path." 


\subsection{Donovan, Hamester and Rattien}

The DHR report contains few quantitative comments in this area "because of the lack of sufficient specifics in the Lovins article and the general uncertainties of costs associated with emerging technologies," but it does point out that Lovins' figures are biased on the soft side and that hard and soft path system costs were not calculated on an equivalent basis. For example, additions to direct fuel use and electrical generating capacity can often use existing transmission/distribution systems either "directly or through 'low-cost' additions to the existing infrastructure," while Lovins assumes that the associated transmission/ distribution systems are replaced with each addition of generating capacity.

Further, "while Lovins insists on life-cycle costing or long-range marginal cost pricing for the hard technologies, there is nothing said of the replacement or decommissioning costs of the soft technologies."

While agreeing with Lovins that "the relatively short payoff investments related to some of the soft path approaches such as use of thermal insulation and solar heating produce faster capital turnover than the longrange investments of central power stations," the DHR report notes that "much of the 'soft-path' approach upon which Lovins relies to reduce demand also require large outlays of long pay back capltal, e.g., the piping system for district heating."

DHR present no estimates of the total capital outlays associated with the two paths but do quote some rough calculations of the ronncil for Energy Independence ${ }^{7}$ on the total costs of solar heating ( $\$ 364$ billion), wind-electricity ( $\$ 520$ billion), and household-sized fluidized bed burners (hundreds of billions of dollars). The DHR report offers these figures "primarily to illustrate how costly rapid across-the-board implementation of the soft technologies might be using current prices and state-of-the-art."

\subsection{University of California, Davis}

The UCD report contains no discussion of the costs of either path because it is felt that such an approach is neither appropriate nor 
accurate. First of all, the relative weights assigned to decision-making criteria (e.g., economics, reliability, environmental impacts) change with the planning horizon. In other words, economic considerations might be the most important criteria in near-term planning (a utility expanding its electrical capacity and trying to decide between nuclear and coal) but become secondary to other criteria like environmental impacts or national security in long-term planning (a government agency plotting the energy future of a nation). Second, even if an economic analysis were appropriate on such a large scale and over such a long time span, it would be woefully imprecise. "One is necessarily concerned with the evolution of energy gystenls uver several generations, and there is no possibility whatever of accurate projections of energy systems costs over these time frames, or even of the precise technical characteristics of technologies." 


\section{INTERNATIONAL IMPLICATIONS OF A DOMESTIC SWITCH FROM HARD TO SOFT}

\subsection{Lovins}

One of the most important advantages seen by Lovins in the "unilateral adoption of a soft energy path by the United States" is that it "can go a long way to control nuclear proliferation - perhaps to eliminate it entirely."

Civilian and military nuclear technology are intertwined: "by no longer artificially divorcing civilian from military nuclear technology we would recognize officially the real driving forces behind proliferation."

Lovins urges the U.S. officially to recognize this, to treat "nonproliferation, control of civilian fission technology, and strategic arms reduction as interrelated parts of the same problem with intertwined solutions." Adoption of this stance, plus phasing out of domestic nuclear power programs, plus redirection of resources diverted from these programs into soft energy development, will serve to "rebottle" the nuclear "genie."

The reason such a scheme would work is that "for at least the next five or ten years, while nuclear dependence and commitments are still reversible, all countries will continue to rely on the United States for the technical, the economic and especially the political support they need to justify their own nuclear programs."

Lovins does not elaborate on the aspects of technical and economic dependence but claims that "in almost all countries the domestic political base to support nuclear power is not solid but shakey. However great their nuclear ambitions, other countries must still borrow that political support from the United States." He goes on to cite opposition to nuclear power in several countries, and states that "nuclear power could not flourish. . . (in Europe). . . if the United States did not want it to."

Jovins considers the cessation of nuclear power generation so important that by "rebottling that genie we could move to energy and foreign policies that our grandchildren can live with. No more important step could be taken toward revitalizing the American dream." 


\subsection{Energy Research Group}

Lovins' criticisms of nuclear power are in turn criticized as "a weary list of risks in operation, human fallibility and malice, risk through greed for profit, violence and coercion, abrogation of civil liberties, guarding of long-lived wastes.. . a shopping list for a technology where everything is to be as bad as possible, in contrast to soft technology where everything is to be as good as possible."

The claim of foreign reliance upon America for the "political" support of nuclear power is denied and is "contrary to the fact of a growing world commitment to nuclear power that is outpacing that of the United States."

Lovins statement that a unilateral cessation of domestic commercial nuclear power activities would lead to a halt in nuclear proliferation is called naive. "If the U.S. were to halt its nuclear energy programs, others might falter temporarily but it is doubtful that they would halt. - . As is often the case, the simple solutions sound attractive but they are unlikely to work. Control of international nuclear proliferation will mean hard work to develop comprehensive safeguards and international agreements. . . ."

\subsection{Donovan, Hamester and Rattien}

The DHR report does not comment on this aspect of Lovins' policy.

\subsection{University of California, Davie}

The UCD report suggests that Lovins' endorsement of soft technologies could be largely motivated by his dislike of nuclear power. The UCD report takes the position that "the question of whether society should choose to exclude all energy derived from nuclear systems is fundamentally separable from the generic issues raised by Lovins." 


\section{SOCIO-POLITICAL IMPACT OF SUCH A SWITCH}

\subsection{Lovins}

Lovins claims that the most profound difference between the two paths is apparent in their domestic socio-political impacts. Both paths "entail significant change. But the kinds of social change needed for. a hard path are apt to be much less pleasant, less plausible, less compatible with social diversity and personal freedom of choice, and less consistent with traditional values than are the social changes that could make a soft path work."

The differences in socio-political impact arise because of differences in scale, diversity, and technological complexity and because of the special problems associated with nuclear power.

First, "the hard path depends on difficult large-scale projects requiring a major social commitment under centralized management." These large-scale projects require a lot of money, as noted in Sect. 3 . In addition, "their similarly heavy demands on other scarce resources skills, labor, materials, special sites - likewise cannot be met by market allocation, but require compulsory diversion from whatever priorities are backed by the weakest constituencies, Quasi-warpowers legislation to this end has already been seriously proposed."

Second, the centralization of these large-scale energy sources leads to industrial clustering and urbanization while "soft technologies can match any settlement pattern." Centralized systems "allocate benefits to suburbanites and soclal. costs to politically weaker rural agrarians" while soft technologies "give everyone the costs and benefits of the energy system he chooses." And centralization "pits central authority against local autonomy" dividing those who use energy from those who supply and regulate it.

Third, "the scale and complexity of centralized grids not only make them politically inaccessible to the poor and weak, but also increase the likelihood and size of malfunctions, mistakes and deliberate disruptions. - . Societies may therefore be tempted to discourage disruption through stringent controls akin to a garrison state. In times of eocial 
stress, when grids become a likely target for dissidents, the sector may be paramilitarized and further isolated from grass-roots politics."

Finally, nuclear power is attacked on each of these points and more. Accidents are possible and potentially disastrous. One effect of an accident at a nuclear plant could be a generic shutdown of all similar plants. The potential of such an accident, it is suggested, might lead the government to consider restrictions on civil liberties. At any rate, "discouraging nuclear violence and coercion requires some abrogation of civil liberties; guarding long-lived wastes agalnst geological or social contingencles implies some form of hierarchical social rigidity or homogeneity to insulate the technological priesthood from social turbu1ence. . . ."

In Lovins' opinion, even if nuclear power were "clean, safe, economic, assured of ample fuel, and socially benign per se, it would still be unattractive because of the political implications of the kind of energy economy it would lock us into."

\subsection{Energy Research Group}

The ERG report quotes an analysis of Lovins' strategy by two professors of ethics" on the need for centralization and argueo that "sone centralized authority is required if society is to achieve equity and justice." At any rate, the soft path probably wouldn't lead to the degree of decentralization envisioned by Lovins. First of all, "local, smallscale institutions are as likely as multinational corporations to adopt the impersonal, bureaucratic style." Second, widespread deployment of the soft techrologles would lead to "considerable infrastructure in manufacturing and distribution, particularly if the benefits of mass production are to be realized."

Finally, the desirability of decentralization is questioned. Lovins' claim that it would lead to a "freer" society "flies in the face of centuries, if not millenia, of human transitions and the desire for less individual effort (or for much of the world, less hardship)." 
Lovins' advocacy of soft technologies for rural villages, urban poor, and less developed countries is characterized as "the 'noble savage' concept resurrected in modern dress."

The ERG report is willing to concede to Lovins that "our society cannot carry into the future with the patterns of 'traditional economic growth' that have characterized the past half-centruy" but questions the capability of the soft path to solve the "wide range of social and political.ills" which he claims for it.

\subsection{Donovan, Hamester and Rattien}

The DHR report contradicts Lovins' estimate of the relative impact of the two paths on life styles: the soft path is said to constrain settlement patterns. To take advantage of economies of scale, users of decentralized technologies will often have to be centralized themselves. Two examples are offered - district heating and household solar heating.

District heating will require a large infrastructure and will have "enormous impacts on the configuration of land use patterns, population density, land values, etc. They may tend to promote clustering to increase population density in order to improve cost efficiency. This population density may not be commensurate with good planning and alternative societal, community and individual goals."

Solar household heating requires storage capacity for periods of inclement weather; this represents a major cost component. Because of the "variance in peak demand between households" it makes sense for households to share capacity, leading to "decreased cost for each member if the delivery distance from storage to use is kept short. Such an arrangement may require a land use as well as community development configuration that is not necessarily desirable or optimal from the standpoint of the community which is faced with many conflicting objectives."

In general, the soft path is seen as giving rise to many social and institutional problems. "These include the problems of new land use patterns (Including clustering) and new social relationships arising from the need to make community decisions about energy supply and the 
requirement that individuals 'get involved' In energy matters in which they may not otherwise be interested."

\subsection{University of California, Davis}

The UCD report points out the increasing overall social-political impact of large-scale energy planning but does not address the specific differences between Lovins' hard and soft paths. 


\section{ENERGY POLICY AS A CATALYST FOR SOCIAL CHANGE}

\subsection{Lovins}

Lovins argues that energy growth and social welfare need not "march forever in lockstep" and that people are ready to accept this notion. Values such as "thrift, simplicity, diversity, neighborliness, humility and craftmanship (are) embodied in a substantial social movement, camouflaged by its very pervasiveness . . our inflated craving for consumer ephemerals is giving way to a search for both personal and public purpose, to reexamination of the legitimacy of the industrial ethic."

Lovins suggests that many "strands of observable social change" are converging on "a profound cultural transformation" and that energy policy could serve as a catalyst and integrating principle in this transformation. He claims that "the most important, difficult, and neglected questions of energy strategy are not mainly technical or economic but rather social and ethical. They will pose a supreme challenge to the adaptability of democratic institutions and to the vitality of our spiritual life."

\subsection{Energy Research Group}

The ERG report agrees with Lovins that "growth does not produce equity (although some growth is probably necessary to achieve equity on a national basis, and considerable growth to achieve it internationally)."

The repurt disagrees that energy can be used as a major instrument to affect social change. Since characteristic "lead-times" of political and economic structures are shorter than for energy systems, "it would seem that the changes would first have to be made in the structure of the economy and political thinking. Nor do we believe that energy strategy should be used as the means to manipulate a path for society; rather, entrgy policies must: be developed in consonance with social objectives that have been openly agreed upon."

\subsection{Donovan, Hamester and Rattien}

The DHR report does not address this issue directly. 


\subsection{University of California, Davis}

The UCD report admits the interdependence between energy R\&D strategy decision and broad social objectives but questions Lovins' estimate of the strength of this link. However, it agrees that "although Lovins' assertion (that the design of energy systems must follow from our understanding of what we wish our pattern of energy end-uses to be) is more of an ideal than a practical methodology, it correctly shifts the emphasis in energy system planning away from the producer perspective to that of the user." 


\section{REFERENCES}

1. A. B. Lovins, Soft Energy Paths: Toward a Durable Peace, Ballinger Publishing Co., Cambridge, Massachusetts, 1977.

2. "Scale, Centralization, and Electrification In Energy Systems." paper presented at Symposium on Future Strategies of Energy Development, Oak Ridge Associated Universities, Oak Ridge, Tennessee, October 1976.

3. A. B. Lovins, "Energy Strategy: The Road Not Taken," Foreign Affairs (October 1976).

4. Energy Research Group, Inc., Exclusive Paths and Difficult Choices: An Analysis of Hard, Soft and Moderate Energy Paths (June 1977).

5. Donovan, Hamester \& Rattien, Inc., Review of Recent Demand/Supply Projections (July 1977).

6. P. P. Craig and R. Mathans, Complaint Energy Paths - Comments on "Energy Strategies - The Road Not Taken," Council on Energy and Resources, University of California (Davis) (August 1977).

7. Council on Energy Independence, Comments on Article by Amory $B$. Lovins, Chicago, Illinois (May 1977).

8. A. B. Lovins, Invited Testimony for Hearings on the Costs of Nuclear Power before the Environment, Energy, and Natural Resources Subcommittee of the Committee on Government Operation, U.S. House of Representatives, Sept. 21, 1977.

9. G. W. Pickering and M. N. Maxey, "The Road Not Taken - And Wisely So: A Path too Soft to Travel," pp. 77-110, in Soft vs Hard Energy Paths, Charles Yulish Associates, Inc., New York, June 1977. 
THIS PAGE

\section{WAS INTENTIONALLY LEFT BLANK}


Appendix A

\section{THE COST OF NUCLEAR-GENERATED ELECTRICITY IN THE MID-1980s, AS CALCULATED BY LOVINS}

Lovins' estimate of the whole-system cost of supplying a unit of energy, at the point of end use is derived as follows:

1.

\begin{tabular}{lc}
\multicolumn{1}{c}{ Item } & $1976 \$ / \mathrm{kWe}$ \\
\cline { 2 - 2 } Generating station & 929 \\
Initial core & 100 \\
Fuel cycle facilities & 76 \\
Transmission capacity & 86 \\
Distribution capacity & 525 \\
& $\$ \frac{\$ 1716}{\mathrm{~kW}}$ installed
\end{tabular}

2. $\$ 1716 \div 0.55$ (plant factor) $=\$ 3120 / \mathrm{kW}$ sent out

3. $\$ 3120 \times \frac{100}{100-10.7}(10.7 \%$ transmission and distribution 1osses $)$ $=\$ 3494 / \mathrm{kW}$ delivered

4. $\$ 3494 / \mathrm{kW} \times 67.1 \frac{\mathrm{kW}}{\mathrm{bbl} \cdot \mathrm{day}}=\$ 234,450 / \mathrm{bb1} \cdot \mathrm{day}$

The unit costs contributing to this calculation are derived in Chapter 6 of Ref. 1 and generally are comparable.with other estimates of mid-1980s start-up costs for nuclear power stations and associated facilities. However, the method of calculation might be questioned on several counts.

First of a11, existing transmission and distribution (T\&D) infrastructure is ignored and it is assumed that every new $\mathrm{kW}$ of electrical generating capacity requires an associated $\mathrm{kW}$ worth of $\mathrm{T} \& \mathrm{D}$ equipment actually $1.12 \mathrm{~kW}$ worth to account for an assumed T\&D loss of $10.7 \%$ $\left(\frac{1}{1-0.107}=1.12\right)$. Then it is assumed that both the generating station and $T \& D$ equipment deliver only $55 \%$ of the electricity they were designed to supply (a lifetime average plant factor of 0.55 is assumed to be typical of a large nuclear plant; the same factor is assumed for the associated marginal T\&D equipment for lack of a better factor). Thus, 
Lovins assumes the installation of $2.04 \mathrm{kWe}$ of generating capacity and $2.04 \mathrm{kWe}$ of $\mathrm{T} \& \mathrm{D}$ capacity to deliver $1 \mathrm{kWe}$ to a user.

However, the nuclear-generated $k W e$ is then compared, at the point of end use, in Table 1, with energy in other forms from other systems, e.g., with a kWt from solar heating. To put the two different kinds of energy on an equivalent basis, one might assume conversion of the electricity to heat in a heat pump with a coefficient of performance of 2.5 and a cost of $\$ 200 / \mathrm{kWe}$ (Lovins' example on p. 135 of Ref. 1). Calculating the cost of energy delivered as heat and adding the cost of the heat pump gives

$$
\frac{\$ 234,450 / \mathrm{bbl} \cdot \mathrm{day}}{2.5}+\frac{\$ 2000 \mathrm{kWe}}{2.5 \mathrm{kWt} / \mathrm{kWe}} \times 67.1 \frac{\mathrm{kWt}}{\mathrm{bbl} \cdot \mathrm{day}}=\$ 99,148 / \mathrm{bbl} \cdot \mathrm{day}
$$

Thus, when the whole-system costs are put on an equivalent basis, the cost of nuclear generated electricity becomes comparable to that of $100 \%$ solar space heating in Table 1.

It might also be noted that the cost of electricity is a shared cost in that while a $\mathrm{kW}$ of solar space heating serves only the householder, a $\mathrm{kW}$ of electricity delivered to a neighborhood is shared by several homes the cost of that $\mathrm{kW}$ may be borne by a neighbor while the householder is away from home.

These and other cautions described in the text should be observed when using Table 1 to compare the costs of the various "hard" and "soft" technologies. 
ORNL/TM-6233

Dist. Category UC- 80

\section{Internal Distribution}

1. T. D. Anderson

2. S. Baron

3. H. F. Bauman

4. T. K. Bernard

5. H. I. Bowers

6. H. Braunstein

7. J. G. Delene

8. H. L. Falkenberry

9. B. H. Fitzgerald

10. W. Fulkerson

11. L. C. Fuller

12. J. F. Harvey

13. C. R. Hudson II

14. J. D. Jenkins

15. M. A. Kuliasha

16. M. Levenson
17. M. L. Myers

18. H. Postma

19. T. H. Row

20. Myrtleen Sheldon

21-120. R. L. Simard

121. G. R. Smolen

122. I. Spiewak

123. H. E. Trammell

124. D. B. Trauger

125. C. West

126. R. M. Young

127-128. Central Research Library

129. Document Reference Section

130-131. Laboratory Records Department

132. Laboratory Records, ORNL RC

133. ORNL Patent Office

\section{External Distribution}

134. Director, Program Planning and Analysis, Nuclear Energy Programs, DOE, Washington, DC 20545

135-139. M. W. Koehlinger, Program Planning and Analysis, Nuclear Energy Programs, DOE, Washington, DC 20545

140. S. E. Miller, Program Planning and Analysis, Nuclear Energy Programs, DOE, Washington, DC 20545

141. Bill Rice, Program Planning and Analysis, Nuclear Energy Programs, DOE, Washington, DC 20545

142. Saul Strauch, Office of Fuel Cycle Evaluation, Nuclear Energy Programs, DOE, Washington, DC 20545

143. ח. F. Mathes, Office of Fuel Cycle Evaluation, Nuclear Energy Programs, DOE, Washington, DC 20545

144. D. R. Israel, Office of Energy Research, DOE, Washington, DC 20545

145. Edward Blum, Policy and Evaluation, DOE, Washington, DC 20545

146. Robert McFarren, Economic Regulatory Administration, DOE, Washington, DC 20545

147. Director, Research and Technical Support Division, DOE-ORO

148. Director, Reactor Division, DOE-ORO

149. H. W. Behrman, DOE-ORO

150. Paul Craig, Department of Applied Science and Energy and Resources Council, University of California, Davis, Davis, CA 95616

151. Ian Forbes, Energy Research Group, 400-1 Totten Pond Road, Waltham, MA 02154 
152. Hans Hamester, Donovan, Hamester and Rattien, Inc., 1055 Thomas Jefferson Street, NW, Suite 414, Washington, DC 20007

153-291. For distribution as shown in TID-4500 under UC-80, General Reactor Technology 